\title{
The Effect of Cryogenic Treatment on Mechanical Properties, Wear and Corro- sion Resistance of Aluminium Alloy AW7075
}

Ludmila Kučerová1, Jiř́ Hájek², Jan Vítek²

${ }^{1}$ Regional Technological Institute, UWB in Pilsen, Univerzitní 8, 30100 Plzeň, Czech Republic. E-mail: skal@rti.zcu.cz

${ }^{2}$ Department of Material Science and Technology, UWB in Pilsen, Univerzitní 8, 30100 Plzeň, Czech Republic. Email: hajek@kmm.zcu.cz,kunc.jenik@seznam.cz

Effect of addition of cryogenic treatment to a standard heat treatment of aluminium alloy AW 7075 was tested in this work. Used heat treatment consisted of solution annealing at $470{ }^{\circ} \mathrm{C}$ for two hours and precipitation aging treatment at $130^{\circ} \mathrm{C}$ for 14 hours, $120^{\circ} \mathrm{C}$ for 24 hours or natural aging at room temperature for 60 days. One set of samples was processed by solution annealing and aging treatment and the second set of samples incorporated 24 hours long cryogenic treatment at $-185^{\circ} \mathrm{C}$ between the same solution annealing and aging. Both sets of samples were characterised by tensile testing, notch impact testing, hardness measurement, microstructure analysis and wear and corrosion resistance tests. Obtained results were compared for corresponding processing with and without cryogenic treatment. While impact toughness and corrosion resistance were decreased by cryogenic treatment, tensile strength and wear resistance were on the other hand improved.

Keywords: aluminium alloy, cryogenic processing, heat treatment

\section{Introduction}

The idea of improving mechanical properties by cryogenic treatment is rather old, as can be deduced form the stories of Swiss watchmakers burying newly made parts in snow, or companies which would "age" castings by putting them outside during the winter [1]. Modern approach to cryogenic treatment started to appear in the 1930s aiming to improve the performance of tool steels. The technology is recently used in more sophisticated way for instance for production of components by NASA [2,3].

Among the materials which can benefit from cryogenic treatment are besides steels also some nonferrous materials, such as copper [4] and aluminium alloys [5-13]. This work concentrates at aluminium alloy AW 7075, which is precipitation-hardened material used in applications requiring high strength and good wear or corrosion resistance [5].

It was reported for aluminium alloys processed by cryogenic treatment [6-8], that the number of lattice defects decreased in comparison to un-treated sam-

Tab. 1 Chemical composition of used alloy in weight $\%$

\begin{tabular}{|c|c|c|c|c|c|c|c|}
\hline $\mathrm{Cu}$ & $\mathrm{Mg}$ & $\mathrm{Zn}$ & $\mathrm{Si}$ & $\mathrm{Fe}$ & $\mathrm{Cr}$ & $\mathrm{Mn}$ & $\mathrm{Ti}$ \\
\hline 1.90 & 2.40 & 5.27 & 0.85 & 0.48 & 0.26 & 0.15 & 0.08 \\
\hline
\end{tabular}

\subsection{Heat treatment}

All the samples used in this work were annealed at $470{ }^{\circ} \mathrm{C}$ for two hours and quenched in water (Fig. 1). ples. This resulted in displacement of the atoms of alloying elements and the subsequent growth of secondary phases. Measurement of residual stresses also revealed that cryogenic treatment removed tensile residual stresses and created small amount of compressive residual stresses [6].

Wider application of cryogenic treatment is at the moment limited by rather unpredictable results of the treatment on various materials, higher processing costs and still not completely understood principles of improvement of mechanical, tribological and corrosion properties. More research work in this area is therefore still needed.

\section{Experimental program}

\subsection{Material}

Aluminium alloy AW 7075 (AlZnMgCu1.5) was used for experimental program. It is precipitation hardened aluminium alloy, containing further zinc, copper and manganese. Exact chemical composition of the alloy given in Tab. 1 was determined by GDOES analysis, using GDS-500 machine.
One set of the samples underwent 24 hour cryogenic treatment at $-185^{\circ} \mathrm{C}$ prior to subsequent precipitation annealing. The second set of samples was directly precipitation annealed. Three annealing temperatures 
were tested, $120^{\circ} \mathrm{C}$ with 24 hour hold, $130{ }^{\circ} \mathrm{C}$ with 14 hour hold and natural precipitation at room temperature for 60 days. For comparison, the same precipitation annealing was always applied to samples with and without cryogenic pre-treatment. Cryogenic treatment was carried out in European Cryogenic Institute, s.r.o.

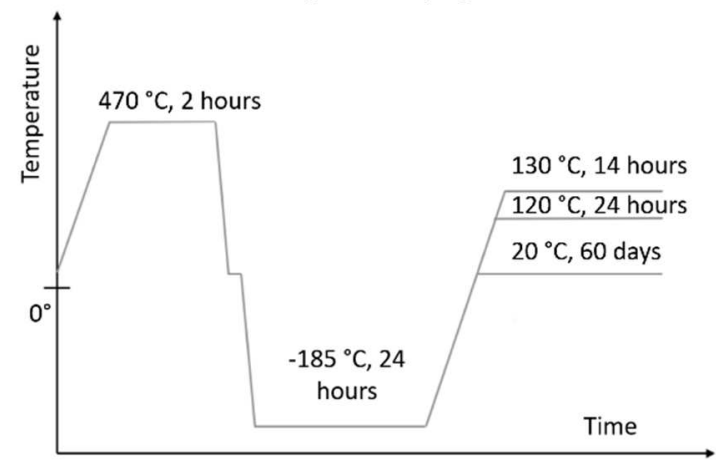

Fig. 1 Heat treatment schedule with overwiew of precipitation annealing parameters

\subsection{Evaluation}

Mechanical properties of all samples were evaluated by tensile test of standard samples with $10 \mathrm{~mm}$ diameter and $100 \mathrm{~mm}$ gauge length, carried out at Zwick Roell Z 250, according to CSN EN ISO 68921. Two samples were tested for each processing variant and average values are given in the graphs.

Impact toughness was measured by Charpy impact test, according to ČSN EN ISO 148-1, using standard samples with dimensions of $10 \times 10 \times 55 \mathrm{~mm}$ and "V" shaped notch with the depth of $2 \mathrm{~mm}$. Brinell hardness was carried out according to ČSN EN ISO 6505. Two samples were tested for each processing variant and average values are given in the graphs.

Brinell hardness was determined as an average value from three measurements for each processing variant. Following testing parameters were used for all samples: load of $62.5 \mathrm{~kg}$, loading hold of $10 \mathrm{~s}$, ball diameter of $2.5 \mathrm{~mm}$.

Wear resistance was evaluated by pin on disc test according to ASTM G99 using an equipment which was built at Department of Material science, Faculty of Mechanical Engineering of UWB in Pilsen. Samples were polished prior to the test and the wear was determined by precise weigh loss measurement. Scales with the accuracy of $10^{-4} \mathrm{~g}$ were used for evaluation of sample weight. Three circular grooves were produced at each sample using WC ball with $6 \mathrm{~mm}$ diameter for 1500 cycles with rotation speed of $158 \mathrm{rev} / \mathrm{min}$ and load of $2 \mathrm{~N}$. The method of weight loss measurement was chosen because of significant plastic deformation of the surfaces of the grooves, which would, made the measurement of the width and depth of the groove very difficult. All the above mentioned tests were carried out at room temperature.

An Olympus BX61 light microscope and a Zeiss EVO 25 scanning electron microscope were used to document the microstructure of the alloy after various heat treatments with $\mathrm{LaB}_{6}$ cathode. Metallographic sections were prepared in a standard way and samples were etched in Keller etchant for several seconds to reveal the microstructure.

Corrosion resistance was tested in QFOG_CCT600 chamber, according to ČSN EN ISO 9227. Testing was carried out in salt fog with concentration of $5 \%, \mathrm{pH}$ 6.5-7.2 for 96 hours at the temperature of $35^{\circ} \mathrm{C}$. A method of weight loss measurement was applied for evaluation of corrosion resistance. Weight loss of each sample was determined after clearing of corrosion products in $65 \%$ of nitride acid according to ČSN ISO 8407.

\section{Results and discussion}

\subsection{Mechanical properties}

Yield and ultimate tensile strengths of samples with and without cryogenic treatment with subsequent precipitation annealing at $120^{\circ} \mathrm{C}$ were similar, reaching around $600 \mathrm{MPa}$ and $648 \mathrm{MPa}$ respectively (Fig. 2, Tab. 2). The total elongation can be also considered similar, as the difference was only $1 \%$ in favour of the sample without cryogenic treatment.
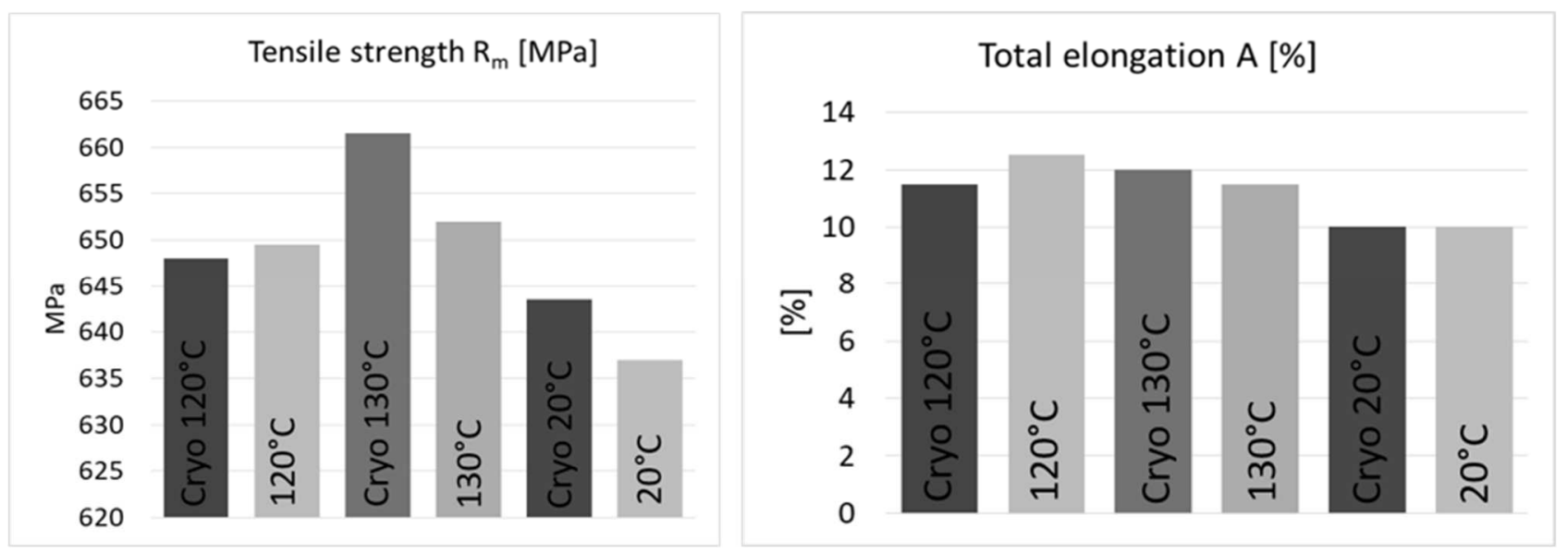

Fig. 2 Comparison of ultimate tensile strength and total elongations of samples with and without cryogenic treatment 
Samples with precipitation annealing at $130{ }^{\circ} \mathrm{C}$ showed a small positive effect of cryogenic treatment on tensile strength. Both the yield and ultimate tensile strength were by $10 \mathrm{MPa}$ higher than for the corresponding sample without cryogenic treatment. Total elongation could be considered the same for both samples, the difference being only $0.5 \%$. The sample with cryogenic treatment and precipitation annealing at $130{ }^{\circ} \mathrm{C}$ reached the highest yield strength of 613 $\mathrm{MPa}$ and tensile strength of $652 \mathrm{MPa}$ of all the samples used in this study.
$5 \mathrm{MPa}$ increase in yield and ultimate tensile strengths was observed for samples with cryogenic treatment and natural aging in comparison with samples which were only naturally aged without previous cryogenic treatment. The strengths and elongations of naturally aged samples were generally lower than those obtained for precipitation annealed samples, reaching yield strengths around $493 \mathrm{MPa}$, tensile strengths around $640 \mathrm{MPa}$ and total elongation of $10 \%$.

Tab. 2 Overview of mechanical properties and weight loss after tribological test

\begin{tabular}{|l|l|l|l|l|l|l|l|l|}
\hline Heat treatment & Re $[\mathrm{MPa}]$ & $\begin{array}{l}\mathrm{Rm} \\
{[\mathrm{MPa}]}\end{array}$ & $\mathrm{A}[\%]$ & $\mathrm{HWB}$ & $\begin{array}{l}\mathrm{KV} \\
{[\mathrm{J}]}\end{array}$ & $\begin{array}{l}\text { Weight loss } \\
\text { wear }[\mathrm{g}]\end{array}$ & $\begin{array}{l}\text { Weight loss - } \\
\text { corrosion }[\mathrm{g}]\end{array}$ \\
\hline Cryo $120^{\circ} \mathrm{C}$ & $598 \pm 7$ & $648 \pm 6$ & $12 \pm 0$ & $171 \pm 1$ & $14 \pm 1$ & 0.00050 & 0.0111 \\
\hline $120^{\circ} \mathrm{C}$ & $596 \pm 1$ & $650 \pm 1$ & $13 \pm 0$ & $172 \pm 1$ & $15 \pm 1$ & 0.00090 & 0.0100 \\
\hline Cryo $130^{\circ} \mathrm{C}$ & $613 \pm 0$ & $662 \pm 1$ & $12 \pm 0$ & $171 \pm 1$ & $12 \pm 1$ & 0.00060 & 0.0109 \\
\hline $130^{\circ} \mathrm{C}$ & $603 \pm 3$ & $652 \pm 2$ & $12 \pm 0$ & $174 \pm 1$ & $13 \pm 1$ & 0.00063 & 0.0080 \\
\hline Cryo $20^{\circ} \mathrm{C}$ & $495 \pm 2$ & $644 \pm 3$ & $10 \pm 0$ & $137 \pm 2$ & $22 \pm 0$ & 0.00060 & 0.0105 \\
\hline $20^{\circ} \mathrm{C}$ & $489 \pm 1$ & $637 \pm 0$ & $10 \pm 0$ & $135 \pm 1$ & $23 \pm 0$ & 0.00067 & 0.0099 \\
\hline
\end{tabular}

Brinell hardness was measured for all the samples (Fig. 3, Tab.2). The samples with aging treatment temperatures of $120{ }^{\circ} \mathrm{C}$ and $130{ }^{\circ} \mathrm{C}$ possessed the same hardness around $170 \mathrm{HBW}$, regardless of cryogenic treatment. Both samples with natural aging at room temperature had lower hardness of $135 \mathrm{HBW}$. It can be therefore stated that significant effect of cryogenic treatment on hardness was not observed.

\section{Hardness [HBW]}

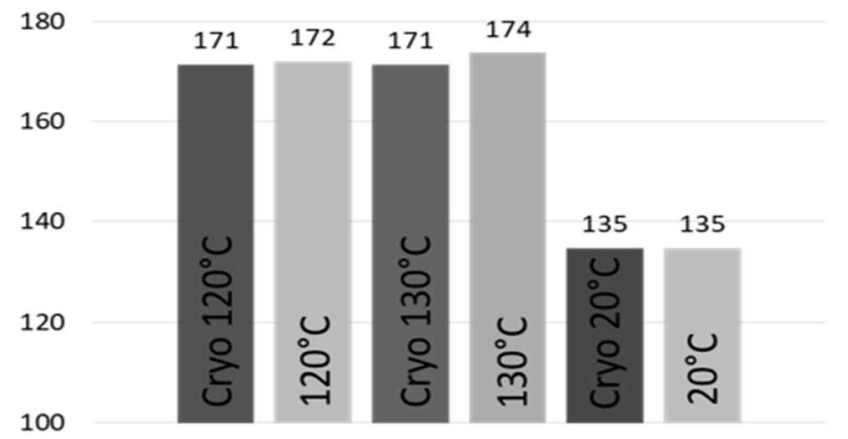

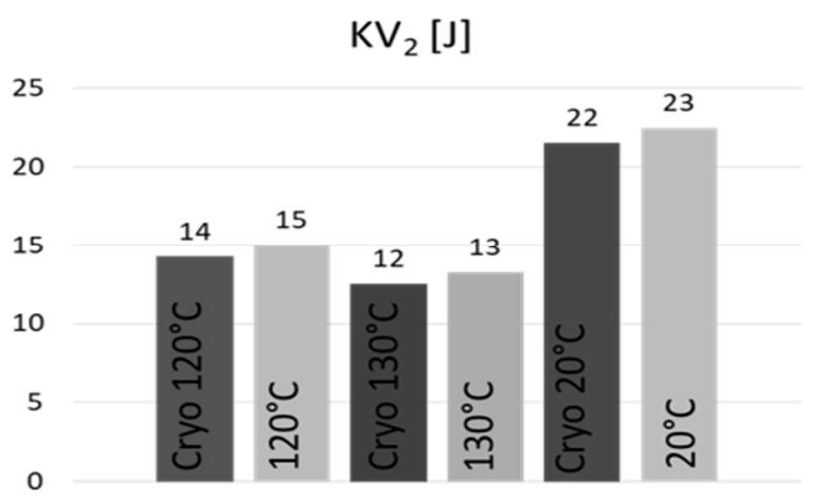

Fig. 3 Comparison of Brinell hardness and impact toughness of samples with and without cryogenic treatment

The results in Fig.3 indicate that cryogenic treatment decreased the impact toughness of samples for all three tested processing variants. Considering the scatter of the values and low number of tested samples (two), this drop is not very significant for any processing variant. However the positive effect of cryogenic treatment on impact toughness could be excluded for used parameters of heat treatment.

\subsection{Wear resistance}

Pin on disc test was used to evaluate wear resistance provided by produced processing variants. Even though the evaluation by weight reduction method depend strongly on the precision of the weight measurements, there seems to be a rather clear trend showing better wear resistance of samples which underwent cryogenic treatment in comparison to the corresponding samples without cryogenic treatment (Tab.2). The most significant difference can be seen in samples with precipitation annealing at $120^{\circ} \mathrm{C}$. In this case, cryogenic treatment decrease the amount of removed material nearly by a halve, with weight loss decreasing from 0.0009 to $0.0005 \mathrm{~g}$.

It could be therefore assumed that during the heat treatment with a cryogenic step, stresses are released in sub-microscopic scale, which however doesn't have a significant effect on mechanical properties of this alloy. Small increase of the amount of precipitated particles could be further expected, which would be responsible for increased wear resistance of the alloy. 


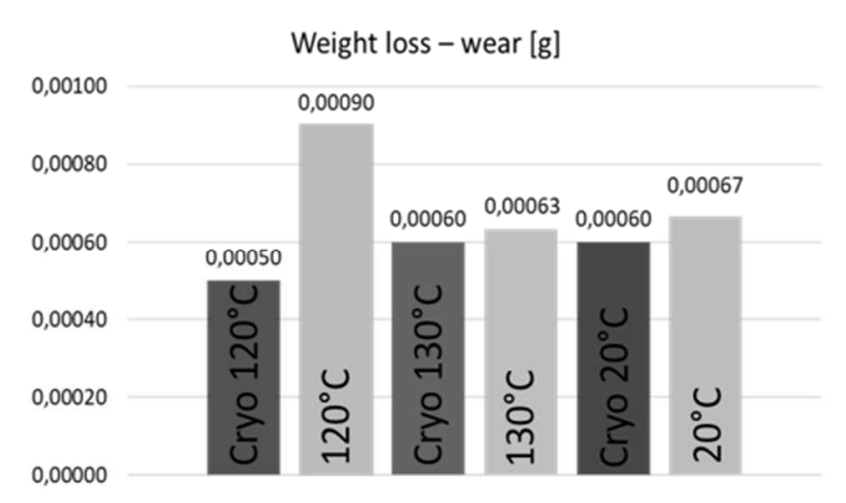

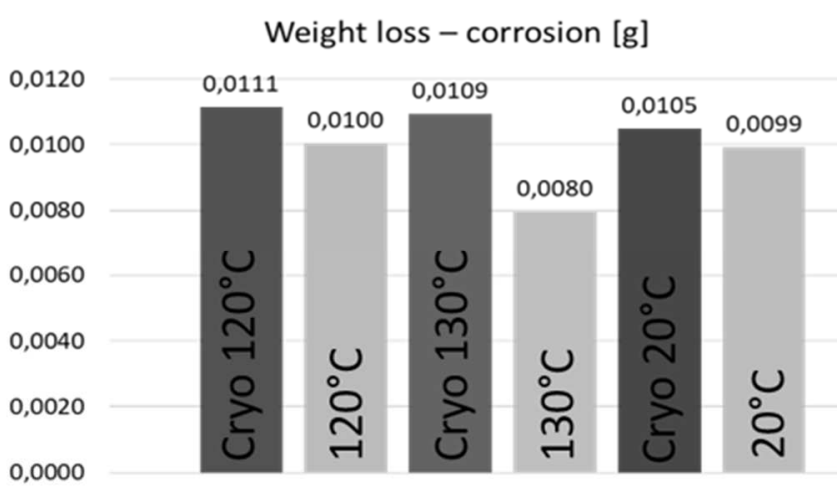

Fig. 4 Comparison of weight loss of samples with and without cryogenic treatment for wear resistance test and corrosion resistance test

While mechanical properties and wear resistance of the samples after cryogenic treatment showed only small differences from the samples which underwent conventional treatment, it could be interesting to compare these results to the work of Sejzu et al. [10]. They reported significant improvement of tensile strength, hardness and wear resistance of AW 7075 alloy after cryo-rolling treatment, while the total elongation also markedly decreased. It might suggest that cryogenic treatment would be beneficial for this particular alloy when the cryogenic step is carried out during the forming, rather than during the subsequent heat treatment of the alloy.

\subsection{Corrosion resistance}

Corrosion resistance of all samples was tested be

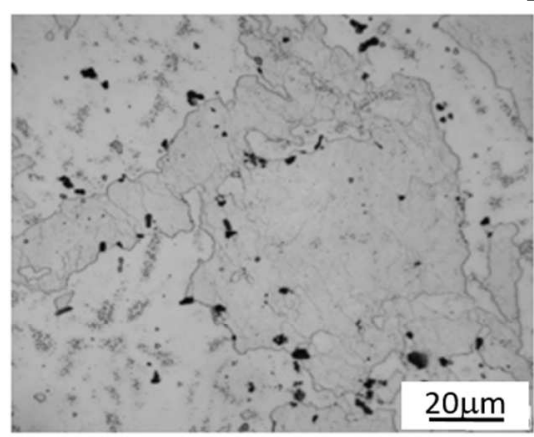

a)

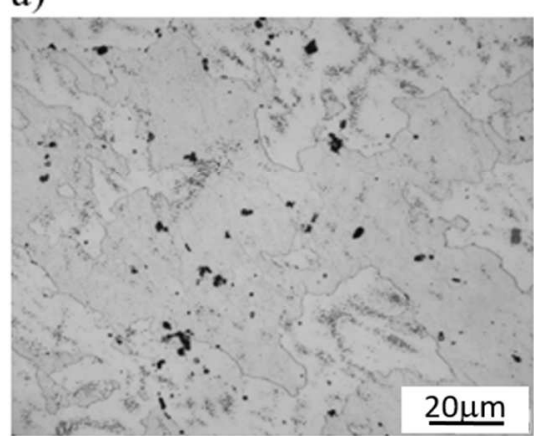

d)

\begin{abstract}
e)
\end{abstract}
Fig. 5 Light microscopy of samples without cryogenic treatment (a-c), precipitation annealed at $130{ }^{\circ} \mathrm{C}$ (a), $120{ }^{\circ} \mathrm{C}$ (b), $20^{\circ} \mathrm{C}$ (c). Light microscopy of samples with cryogenic treatment (d-f), with subsequent precipitation annealed at $130{ }^{\circ} \mathrm{C}(\mathrm{d}), 120{ }^{\circ} \mathrm{C}(\mathrm{e}), 20$ ${ }^{\circ} \mathrm{C}(f)$. exposition of samples to a salt spray for 96 hours. Corrosion products were after the test removed by etching and the weight loss was evaluated (Tab.2, last column, Fig. 4). For all three processing variants used in this work, the cryogenic treatment resulted in the decrease of corrosion resistance in comparison to the same processing without cryogenic treatment step. Correct application of etching method was verified by an unlinear dependence of weight loss on etching time.

\subsection{Microstructure analysis}

The microstructure of all the samples consisted of the grains of $\alpha$-phase with the size of 50-350 $\mu \mathrm{m}$ (Fig. 5). Detailed images by scanning electron microscopy revealed sub-grains with the sizes of 2-10 $\mu \mathrm{m}$ (Fig. 6).

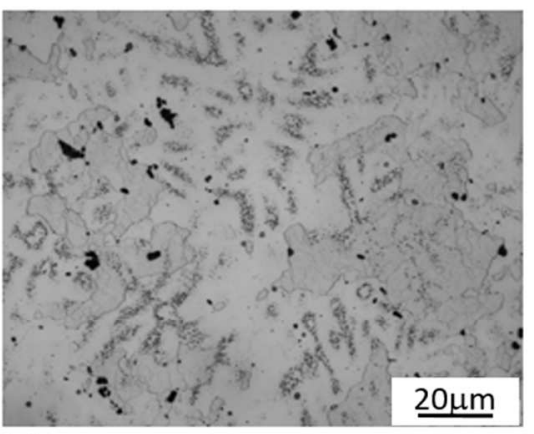

b)

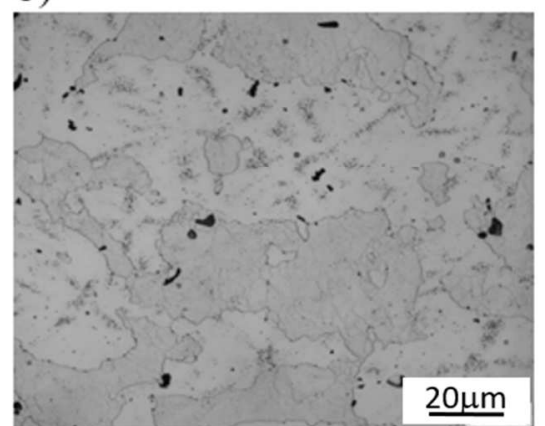

e)

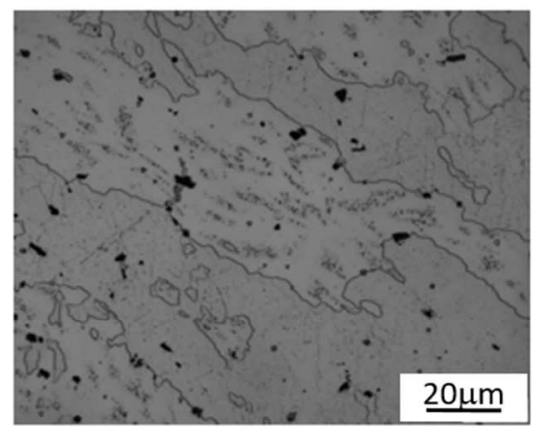

c)

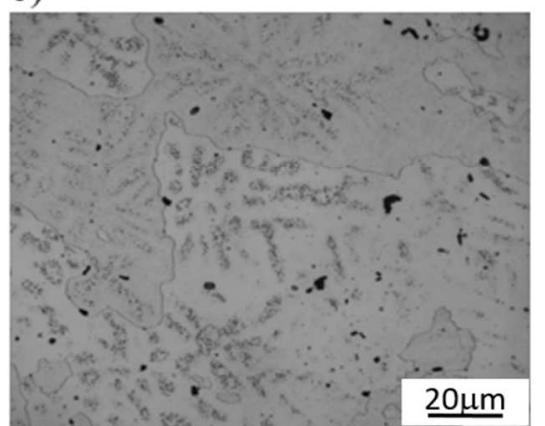

f) 


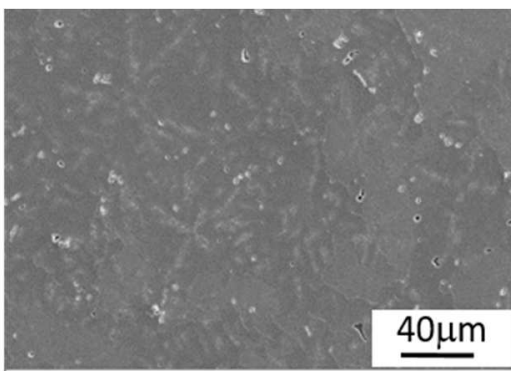

a)

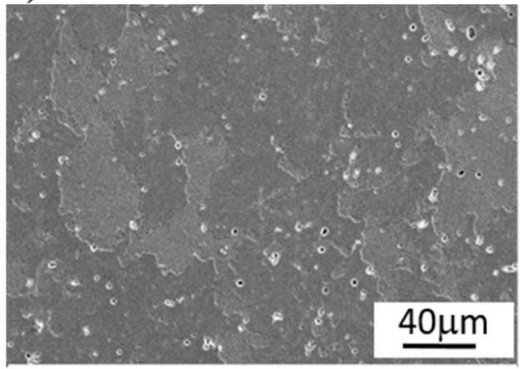

d)

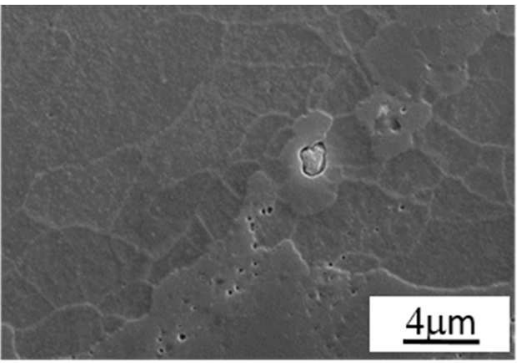

b)

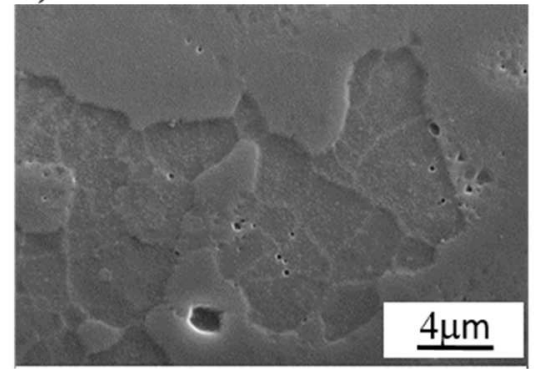

e)

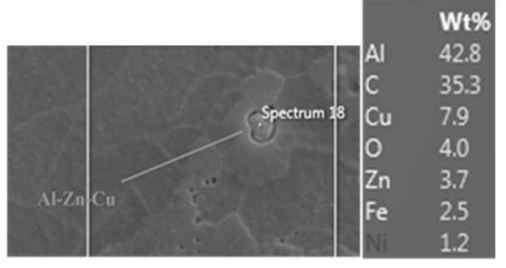

c)

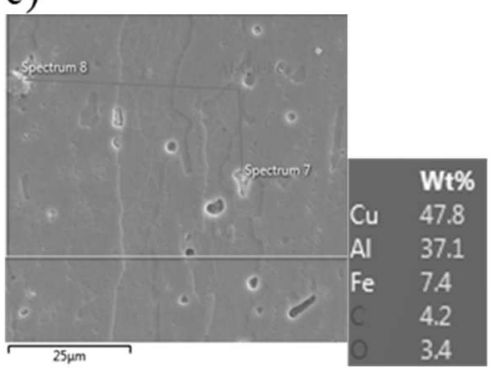

f)

Fig. 6 Scanning electron microscopy of samples annealing at $120^{\circ} \mathrm{C}$ without prior cryogenic treatment (a-c). Details of $\mathrm{Al}-\mathrm{Zn}$-Cu particle (b) and point chemical analysis (c) by EDS. Scanning electron microscopy of samples with cryogenic treatment and subsequent annealing at $120^{\circ} \mathrm{C}(d-f)$. Details of Al-Cu-Fe particles (e) and point chemical composition (f) by EDS.

In all the samples were observed darker areas with dendritic morphology, consisting of large numbers of very fine dimples. They originated from particles, which were released from the surface of metallographic section during the etching, as no holes/dimples were observed on polished samples prior to etching. Typical representatives of remaining particles were analysed by EDS, revealing the presence of intermetallics of $\mathrm{Al}-\mathrm{Zn}-\mathrm{Cu}$ (Fig. 6c) with rather spherical shape and the size of 1-4 $\mu \mathrm{m}$ and larger Al-Fe-Cu intermetallics (Fig. 6f).

\section{Conclusions}

Cryogenic treatment step was incorporated into heat treatment of AW 7075 aluminium alloy with three different temperatures of precipitation annealing. The effect of cryogenic treatment on mechanical properties and wear and corrosion resistance was than evaluated.

Yield and ultimate tensile strengths of samples with precipitation annealing at $130^{\circ} \mathrm{C}$ and with natural aging were improved by cryogenic treatment. The effect on tensile properties of samples with precipitation annealing at $120^{\circ} \mathrm{C}$ was negative. The effect of cryogenic treatment on hardness was negligible, only for samples with precipitation annealing at $130{ }^{\circ} \mathrm{C}$ did the hardness slightly drop after cryogenic treatment. Impact toughness was slightly decreased by cryogenic treatment for all three processing variants. While wear resistance did improve for all three processing variants after incorporation of cryogenic treatment, the corrosion resistance was on the other hand decreased.

It could be therefore generally stated that for AW
7075 aluminium alloy, the benefits of cryogenic treatments lie mainly in increased wear resistance and for some temperatures of subsequent precipitation treatment; tensile strength could be also improved without compromising ductility. Slight improvement of tensile strength and wear resistance could be contributed to small increase of the number of precipitates due to cryogenic treatment. The relive of residual stresses due to cryogenic treatment was on the other hand rather insignificant and didn't markedly improved other mechanical properties of the alloy.

\section{Acknowledgements}

This contribution has been prepared under project LO1502 'Development of the Regional Technological Institute' under the auspices of the National Sustainability Programme I of the Ministry of Education of the Czech Republic aimed at supporting research, experimental development and innovation.

The authors would also like to acknowledge the contribution of European Cryogenic Institute, s.t.o., which carried out the cryogenic treatment of the samples.

\section{References}

[1] GU, K. X. et al. (2000). The Effect of Cryogenic Treatment on the Microstructure and Properties of Ti-6Al-4V Titanium Alloy. In: Materials Science Forum, Vols. 747-748, pp. 899-903.

[2] CHEN, P., MALONE, T., BOND, R., TORES, P. (2000). Effects of Cryogenic Treatment on the Residual Stress and Mechanical 
Properties of an Aerospace Aluminum alloy, George C. Marshall Space Flight Center NASA.

[3] SWEENEY Jr., T.P. (1986). Deep Cryogenics: the Great Cold Debate, Heat Treating, In: Cryogenic, Vol. 18, No. 2, pp. 28-32.

[4] VILLAFUERE, J. (2000). Improving ContactTube Performance Through Cryogenics. In: Welding J., October, pp. 45-48.

[5] LULAY, K. E., KHAN, K., CYAAYA, D. (2002). The Effect of Cryogenic Treatments on 7075 Aluminum Alloy (2002). Engineering Faculty Publications and Presentations. 2. http:// pilotscholars.up.edu/egr_facpubs

[6] MOORE, K., COLLINS, D.N. (1993). Cryogenic Treatment of Three Heat-Treated Tool Steels. In: Key Eng. Mater, Vol. 86-87, pp. 47-54.

[7] SENKOV, O., BHAT, R., SENKOVA, S. (2004) High Strength Aluminum Alloys for Cryogenic Applications. In: Senkov O.N., Miracle D.B., Firstov S.A. (eds) Metallic Materials with High Structural Efficiency. NATO Science Series II: Mathematics, Physics and Chemistry, Vol 146. Springer, Dordrecht.

[8] M.Araghchi, H.Mansouri, R.Vafaei, Yina Guo. (2017). A novel cryogenic treatment for reduction of residual stresses in 2024 aluminum alloy. In: Materials Science and Engineering: $A$, Vol. 689, pp. 48-52.

[9] NÁPRSTKOVÁ N. CAIS, J. INGALDI, M. (2016). Modification of AlSi9CuMnNi Alloy by Antimony and Heat Treatment and Their Influence on Tool Wear after Turning. In: Manufacturing Technology Vol. 16, No. 1 pp. 209-214.

[10] SEJZU, M., GOVINDARAJ, R., PRABHAKARAN, R. (2016). Influence on mechanical properties by cryogenic treatment on aluminium alloy 7075. In: International Journal of Scientific \& Engineering Research, Vol. 7, No. 4, pp. 225-234.

[11] KALINCOVÁ, D., ŤAVODOVÁ, M., KUSMIERCZAK, S. (2017). Analysis of the Properties Aluminium Casting Motorcycle Forks Arm after Compression Test. In: Manufacturing Technology, Vol. 17, No. 5, pp. 717-722.

[12] KUČERA, V., DALIBOR, V. (2017) Influence of the Heat Treatment on Corrosion Behaviour and Mechanical Properties of the AA 7075 Alloy. In: Manufacturing Technology, Vol. 17, No.5, pp. 747-752.

[13] NOVÁKOVÁ, I., MORAVEC, J., KEJZLAR, P. (2017). Metallurgy of the Aluminium Alloys for High-Pressure Die Casting. In: Manufacturing Technology, Vol. 17, No. 5, pp. 804-811. 